\title{
Evaluation of Cooperativeness as a Character Attribute For High Scool Students with Attitudes of Bully, Self-Confident and Avoidant from Bullying
}

\author{
Ayşe AYPAY*
}

\author{
Emine DURMUŞ ${ }^{* *}$
}

\begin{abstract}
The purpose of this study was to evaluate the students who display bully, confident and avoidant attitudes in terms of their "cooperation" as a character attribute. The student relationships attitudes of bully, confident and avoidant were determined through The Student Relationships Attitude Scale (SRAS) developed by Koç (2006). For the "Cooperativeness" characteristic, The Cooperativeness subscale of The Temperament and Character Inventory (TCI) developed by Cloninger and addopted to Turkish by Köse and colleagues (2004) was used. Cooperativeness consists of five lower order traits (social acceptance vs social intolerance, empathy vs social disinterest, helpfulness vs unhelpfulness, compassion vs revengefulness: integrated conscience vs self-serving). The research is conducted on 690 high school students in Ankara. Results indicate that all of the attitutes (confident, avoidant, bully) significantly related to sub dimensions of cooperativeness character attribute. The students who scored higher on cooperativeness scale display more confident attitute than others. The students who scored lower on cooperativeness scale display more bully and avoidant attitutes than others.
\end{abstract}

Key Words: Students, bully attitude, self-confident attitude, avoidant from bullying attitude, cooperativeness.

\footnotetext{
* Res.Assist Ankara University, Faculty of Educational Sciences. ayseaypay@hotmail.com

**Assist.Prof.Dr.Inonu University, Faculty of Education. edurmus@inonu.edu.tr
} 


\section{SUMMARY}

The purpose of this study was to evaluate the students who display bully, confident and avoidant attitudes in terms of their "cooperation" as a character attribute. Cloninger developed a dimensional psychobiological model of personality that accounts for both normal and abnormal variation in two major components of personality, temperament and character. The student relationships attitudes of bully, confident and avoidant were determined through The Student Relationships Attitude Scale (SRAS) developed by Koç (2006). For the "Cooperativeness" characteristic, The Turkish version of Cloninger's subdimension of "cooperativeness" of The Temperament and Character Inventory (TCI) was used. The Turkish version of this instrument adopted by Köse and colleagues (2004). The Temperament and Character Inventory (TCI) is a selfadministered dimensional questionnaire constructed to assess the seven basic dimensions of personality. Each of the seven temperament and character traits is multi-faceted, consisting of several facets or lower order components (Köse et al., 2004).

Cooperativeness consists of the following five aspects or lower order traits: Social Acceptance vs Social Intolerance: High score on this sub-scale is described as tolerant and friendship (low score: Intolerant and unfriendly). Empathy vs Social Disinterest: High score is described as "in other people's shoes" (low score: insensitive). Helpfulness vs Unhelpfulness: High score is described as helpful, supportive, and encouraging, or reassuring (low score: selfcentered, egoistic, or selfish). Compassion vs Revengefulness: High score is described as compassionate, forgiving, charitable, and benevolent (low score: revengeful). Integrated Conscience vs Self-Serving: High score is described as honest, genuinely conscientious, and sincere persons who treat others in a consistently fair manner (low score: opportunistic).

The Student Relationships Attitude Scale (SRAS) is a self administered dimensional questionnaire constructed to assess the three dimensions of relationship attitudes. The attitude dimensions are bully, confident, and avoidant. Bully: High score on this subscale is described as being aggressive and bully with high levels of bullying behavior. Confident: High score on this subscale is described as being confident of interpersonal relationship. Avoidant: High score on this subscale is described as avoiding of behaving as a bully.

Methodology: The sample $(\mathrm{N}=690)$ includes students from three high schools, comprised of 9 through 11th grades in Ankara. In additon to descriptive statistics, t-tests, one-way ANOVAs and Pearson correlations were conducted. The high schools are located in the areas where low and middle SES families live. Ages of the students are between 15-19. The sample includes 376 girls $(54.5 \%)$ and 314 boys $(45.5 \%) .236$ students $(34.2 \%)$ were in 9th grade; 258 students $(37.4 \%)$ were in 10 th grade, and 196 students $(28.4 \%)$ were in 11 th grade. 
Findings: T- Test results point out that apart from confident attitude, there were significant differences between bully and avoidant attitude based on gender. For both bully and avoidant attitudes, mean scores of boys were higher than girls. According to t-test results, there were significant differences between cooperativeness character attribute scores based on gender. Mean scores of girls were higher than boys. These findings indicate that gender is an important factor for both student relationships attitudes and cooperativeness character attribute. Boys were more likely to have bully and avoidant attitudes than girls and girls were more likely to have cooperativeness character attribute than boys. ANOVA results indicated that there were no significant differences among attitudes (bully, confident and avoident) and cooperativeness character attribute scores based on grade levels. Based on these findings, one might claim that grade levels do not make any differences on relationship attitudes and cooperativeness character attribute. After that, analyses carried out to investigate the relationships between the scores of relationships attitudes (bully, confident and avoidant) and the sub-dimensions of cooperativeness character attribute.

Conclusions and Suggestions: Gender was an important variable on student attitudes and cooperativeness character attribute. Boys were more likely to display bully and avoidant attitudes while girls were more likely to display cooperativeness character attribute. Student relationships attitudes and cooperativeness character attribute did not vary significantly based on grade levels. All of the attitutes (confident, avoidant, bully) significantly related to sub-dimensions of cooperativeness character attribute. The students who scored higher on cooperativeness scale were likely to display more confident attitute than others. The students who scored lower on cooperativeness scale were likely to display more bully and avoidant attitutes than others. Students who display bully and avoidant attitudes were similar in terms of cooperativeness character attribute.

For future research;

1. Training programs that focus on cooperativeness character attribute should be developed and their effectiveness should be tested in practice.

2. Studies that focus on the relationships between attitudes and other character attributes may be conducted.

3. Since bully and avoidant attitudes are similar in terms of cooperativeness character attribute, programs to reduce aggression in schools should not only focus on students who display bully attitudes but also target avoidants. 


\title{
Zorba, Kendine Güvenen ve Zorbalıktan Kaçınan Tutumları Sergileyen Lise Öğrencilerinin İş Birliği Yapma Karakter Özelliği Açısından Değerlendirilmesi
}

\author{
Ayşe AYPAY*
}

Emine DURMUŞ ${ }^{* *}$

\begin{abstract}
ÖZ.Bu çalışmanın amacı zorba, güvenli ve kaçınan tutum sergileyen öğrencilerin iş birliği yapma karakter özelliği açısından değerlendirilmesidir. Zorba, güvenli, kaçınan öğrenci ilişkileri tutumları, Koç (2006) tarafından geliştirilen öğrenci ilişkileri tutum ölçeği ile belirlenmiş̧ir. İş birliği yapma karakter özelliği iç̧in Clonninger'in geliştirdiği ve Köse ve arkadaşları tarafindan (2004) Türkçe'ye uyarlanan mizaç ve karakter envanterinin (TCI) iş birliği yapma alt ölçeği kullanılmıştır. İş birliği yapma karakter özelliği beş alt özellikten (sosyal kabullenme-sosyal hoşgörüsüzlük, empati duyma-sosyal ilgisizlik, yardım severlik-yardım sevmezlik, acımaintikamcllı, temiz kalplilik, vicdanlılık-kendine yarar sağlama) oluşmaktadır. Araştırma Ankara ilinde, 690 lise öğrencisinin katılımıyla gerçekleştirilmiştir. Sonuçlar tüm tutumların (zorba, kaçınan ve güvenli) iş birliği yapma karakter özelliği ile anlamlı düzeyde ilişkili olduğunu göstermektedir. İş birliği yapma ölçeğinden yüksek puan alan öğrenciler, diğerlerinden daha fazla kendine güvenen tutum göstermektedir. İş birliği yapma ölçeğinden düşük puan alan öğrenciler de diğerlerinden daha fazla zorba ve zorbalıktan kaçınan tutum göstermektedir.
\end{abstract}

Anahtar Sözcükler: Öğrenci, zorba tutum, kendine güvenen tutum, zorbalıktan kaçınan tutum, iş birliği yapma.

\footnotetext{
* Araş.Gör.Dr. Ankara Üniversitesi Eğitim Bilimleri Fakültesi ayseaypay@hotmail.com

** Yard.Doç. Dr. İnönü Üniversitesi Eğitim Fakültesi edurmus@inonu.edu.tr
} 
Zorba, Kendine Güvenen ve Zorbalıktan Kaçınan Tutumları Sergileyen ... 27

\section{GíRIȘ}

Zorbalık, çocuk ve ergenler için önemli bir kaygı nedeni ve büyük bir sorun olarak bilinmektedir. Zorbalık, Norveç (Olweus, 1993), İngiltere, İtalya, Kanada, Japonya, Amerika, Avusturalya (Espelage ve Swearer, 2003), İsveç ve İrlanda gibi ülkelerde (Fitzgerald, 1999) önemli bir sorun olarak görülmektedir. Olweus'un çalışmalarıyla dikkat çekilen, çocuklar ve ergenler arasında okul zorbalığı konusu, yaklaşık 35 yıldır farklı ülkelerden bir çok araştırmacının çalışmalarına konu olmuştur (Akt. Espelage ve Swearer, 2003). Okullarda zorbalık konusunda ülkemizde de medyaya yansıyan olumsuz haberler ve halkın bu konudaki artan kaygısı, zorbalığın Türkiye için de önemli bir sorun olmaya başladığına işaret etmektedir.

Okul zorbalığı, Olweus'a (1999) göre, "bir ya da daha fazla öğrencinin, bir başka öğrenciye sürekli olarak olumsuz eylemlerde bulunması" olarak tanımlanmaktadır. Olweus (1999), okul zorbalığ olarak tanımlanabilecek eylemlerin şu üç ölçütü karşılaması gerektiğini öne sürmektedir: Saldırgan davranışların kasıtlı olarak zarar vermeye yönelik olması, bu davranışların sürekliliğinin olması ve zorbalığa maruz kalan ile zorbalığı yapan arasında güç dengesinin olmaması. Alanyazında zorbalıkla ilgili tanımlar incelendiğinde, bir çok tanımda, güç ya da prestij kazanmak için bir kişi ya da grup tarafından sistematik bir biçimde ve sürekli olarak sözel ve davranışsal saldırılarda bulunulması bilgisinin yer aldığı görülmektedir (Espelage ve Swearer, 2003).

Türkiye'de zorbalık konusunda yapılan çalışmalara bakıldığında, araştırmaların bir bölümünün (Çınkır ve Karaman-Kepenekçi 2003; Durmuş ve Gürgan, 2005; Öğülmüsş, 1995a; Yurtal ve Cenkseven, 2006), zorbalığın okullarda yaygınlığını belirlemeyi amaçlayan nitelikteki çalışmalar olduğu görülmektedir. Eğitimcilerin okul zorbalığına ilişkin görüşlerinin belirlenmeye çalışıldığı bir araştırmada, eğitimcilerin \%60.16'sının zorbalığa başvuran öğrencileri kişisel sorunu olan öğrenciler olarak algıladığı, \%62.50'sinin de zorbalığa başvuran öğrencilerin sorunlarını nasıl çözeceğini bilemeyen kişiler olduğunu düşündüğü ifade edilmektedir (Çınkır ve Karaman-Kepenekçi, 2003). Lise öğrencileri arasında şiddet ve saldırganlık oranlarını belirlemeyi amaçlayan bir çalışmada (Öğülmüş, 1995a), 1995 yılı verilerine göre, liselerde öğrencilerin paralarının çalınması, özel eşyalarının kaybolması (\%76.4) masa ve sandalyelerin kırılmas1, bunların üzerlerinin kazılması, boya badanasının kirletilmesi olayları (\%74.6) büyük oranda yaşanmaktadır. On yıl sonra yapılan benzer bir çalışmada (Durmuş ve Gürgan, 2005), okul sınırları dışında meydana gelen ve bazı öğrencilerin yaralanmasıyla sonuçlanan kavgaların (\%70.1) yanı sıra, okuldaki çeşitli ögrenci grupları arasında toplu kavga olaylarının da (\%70) sıkça yaşandığı 
ve öğrencilerin paralarının alınması, öğrenci malzemelerinin ve özel eşyalarının kaybolmasının da büyük oranda (\%63.7) yaşanan şiddet ve saldırganlık davranışları olduğu görülmektedir. On yıllık süre içinde şiddetin eşyadan kişilere doğru yön değiştirdiği ortaya çıkmaktadır. Zorbalığın okullarda yaygınlığını inceleyen diğer bir araştırmaya göre, ilköğretim okullarında en çok yaşanan zorbalık türleri itilmek (\%63), küfredilmek (\%57) sevmediği isimlerle çağrılmak (\%56), alay edilmek (\%49), giysi ya da eşyalarına zarar verilmek (\%45) ve hakkında dedikodu yapılmak (\%44) gibi davranışlardır. $\mathrm{Bu}$ araştırmanın diğer bir bulgusu, zorbalığa maruz kalanların büyük bir oranının bu durumu yalnızca arkadaşlarına anlatmalarıdır (Yurtal ve Cenkseven, 2006).

Okullarda meydana gelen bu tür istenmeyen davranışların nedenlerini yalnızca okul ortamında aramak doğru sonuçlara ulaşmayı güçleştirmektedir. Okullarda yaşanan şiddet, saldırganlık ve zorbalık olaylarının nedenini kişi, okul ortamı ve toplum olmak üzere üç grupta ya da düzeyde ele almak mümkündür. İstenmeyen bu davranışlar bu değişkenlerden yalnızca birinin sonucu olarak değil, genellikle bu üç grupta toplanan değişkenlerin etkileşiminin bir sonucu olarak ortaya çıkmaktadır (Öğülmüş, 1995b).

Türkiye'de zorbalık konusunda yapılan araştırmaların diğer bir bölümünde (Pekel-Uludağlı ve Uçanok 2005; Pişkin 2006; Şirvanlı Özen, 2006) zorba ve kurban olma özellikleri belirlenmeye çalışılmıştır. Bu araştırmalardan biri olan Pekel-Uludağlı ve Uçanok'un (2005) çalışma bulgularına göre, kurban ve zorba çocuklar kurban ve zorba olmayan çocuklara göre daha yalnızdır ve akademik başarıları daha düşüktür. Ayrıca kızlar daha çok alaya ve ilişkisel saldırılara maruz kalırken, erkekler daha çok korkutma/sindirme türünden davranışlara maruz kalmaktadır. Pişkin'in (2006) araştırma bulgularına göre, akran zorbalığında zorbalık ve kurbanlık oranları cinsiyetler arasında farklılık göstermektedir. Zorba puanı yüksek olan grup içerisinde erkek öğrencilerin, kurban puanı yüksek olan grup içerisinde de kız öğrencilerin oranı daha yüksektir. Sınıf düzeyi arttıkça zorba ve kurban davranışları açısından bir artma ve azalma görülmemektedir. Aynı araştırmanın diğer bir bulgusuna göre, kurbanların uğradığı en yaygın zorbalık türü \%33 oranında sözlü zorbalıktır. Şirvanlı Özen'in (2006), akran zorbalığına maruz kalmanın olası yordayıcılarını belirlemeyi amaçladığı çalışmasının bulgularına göre, ergen ve çocukların zorbalığa maruz kalışlarında benlik imgesinin önemli bir rolü vardır. Buna göre, zorbalığa maruz kalmanın yordayıcılarından biri olumsuz benlik imgesine sahip olmaktır.

Zorbalığa ilişkin yanlış inanışlar açısından, zorba grupta yer alan öğrencilerle genel grupta yer alan öğrencilerin görüşlerinin karşılaştırmalı 
olarak ele alındığ bir araştırmada (Pişkin, 2006), zorba öğrencilerin \%69.1 oranında, genel gruptaki öğrencilerin de $\% 56.9$ oranında bazı öğrencilerin zorbalığı hakettiğini düşündüğü belirlenmiştir. $\mathrm{Bu}$ araştırmanın bulgularına göre, başkalarını kızdırmanın eğlenceli olduğu düşüncesine zorbalar \%63.2 oranında, genel gruptakiler \%33.5 oranında katılmıştır. Zorba gruptakiler \%61.8 oranında zorbalığın zamanla unutulacağından önemli olmadığını düşünürken, genel gruptakilerin \%46.5'i bu düşünceye katılmıştır. Ayrıca bir zorba ile baş etmenin en etkili yolunun onunla kavga edip, intikam almak olduğu düşüncesi zorbaların \%54.5'i, genel gruptakilerin de \%22.8'i tarafindan doğru bulunmuştur. Bu araştırmanın bulguları zorba grupta yer alan öğrencilerin zorba, zorbalık ve kurban olmaya ilişkin görüşlerinin genel grupta yer alan öğrencilerin görüşlerinden büyük oranda farklılaştığını ortaya koymaktadır. Bu farklılık, zorbalığın, zorba grupta yer alan öğrenciler tarafından yapılması normal kabul edilen bir davranış biçimi olarak görüldüğü şeklinde özetlenebilir.

Alanyazında zorbalık konusunda yurt dişında yapılan araştırmaların sayısında hızlı bir artış gözlenmektedir. Zorbalık konusunda yapılan araştırmalardaki niceliksel artışa paralel olarak, bu araştırmaların konuları itibariyle de çok çeşitlendikleri açıkça görülmektedir. Zorbalık konusunda yapılan araştırmaların bu artan çeşitliliği içinde dikkati çeken bir diğer durum, birçok araştırmacının (Casey, 2004; Cowie, 2004; Derosier ve Marcus, 2005; Fonagy, Twemlow, Vernberg, Sacco ve Little, 2005; Galvin, 2004; Horne, Orpinas, Newman-Carlson ve Bartolomucci, 2004; Limber, 2004; Olweus, 2005; Miller, Kraus ve Veltkamp, 2005; O’Moore ve Minton, 2004; Pietzak, Petersen, Speaker, 1998; Salmivalli, Kaukiainer ve Voeten, 2005; Shaughnessy, 2004; Whitaker, Rosenbluth, Valle ve Sanchez, 2004; Whitted ve Dupper, 2005) okul zorbalığını önlemeye ya da azaltmaya yönelik yaklaşımlar ve programlar geliştirip bu yaklaşım ve programların etkililiğini sınadıkları çalışmalara yönelmeleridir.

Bu tür çalışmaların daha işlevsel olması için; zorbalığa ortam hazırlayan dış faktörler (aile, okul iklimi, arkadaş çevresi vb.) yanında zorba ve kurbanların bireysel özelliklerinin de (cinsiyet, yaş, karakter özellikleri vb.) daha iyi tanımlanması gerekmektedir. Alanyazında yer alan bazı araştırmalarda (Parada, 2006; Pekel-Uludağlı ve Uçanok, 2005; Pişkin, 2006; Yang, Kim ve Kim, 2005) cinsiyetin zorba ve kurban olma durumuyla ilişkisi belirlenmeye çalışılmıştır. Diğer bazı araştırmalarda da (Camodeca ve Goosens, 2005; Endresen ve Olweus, 2001; Espelage, Mebane ve Adams, 2004; Pekel-Uludağlı ve Uçanok 2005; Pişkin ve Ayas, 2005; Swam, Henry, Kelly, 2006;) öz güven, utangaçlık, kaygı, depresyon, yalnızlık, öfke, yabancılaşma ve risk alma, empati, intikam, öz sayg1 gibi bazı bireysel 
değişkenler ile saldırgan davranış arasındaki ilişkiler sorgulanmıştır. Ancak zorbalar ve kurbanların kişiliklerinin önemli bir bölümünü oluşturan tüm karakter özellikleri açısından tanınmaları gerekmektedir.

Öğrencilerin diğer öğrencilerle ilişkilerinde gösterebilecekleri tutumlarda onların sosyal hoşgörü düzeylerinin, empati becerilerinin, yardımsever olup olmamalarının, acıma ve intikam duygularının yoğunluğunun ve ilişkilerinde daha çok vicdan odaklı mı yoksa kendine yarar sağlama odaklı mı olduklarının belirleyici olabileceği düşünülebilir. $\mathrm{Bu}$ özellikler iş birliği yapma karakter özelliğini oluşturan alt boyutları oluşturduğundan, diğer öğrencilerle olan ilişkilerinde farklı tutumlara (zorba, güvenli, kaçınan) sahip olan öğrencilerin iş birliği yapma karakter özelliği açısından değerlendirilmeleri de önemli görülmektedir. Alanyazında saldırgan ve şiddet davranışlarının iş birliğ i yapma karakter özelliği ile negatif yönde ilişki gösterdiğine dair bulgular vardır (Cloninger, 1987; Nagoshi, Walter, Muntaner ve Haertzen, 1992; Ruchkin, Eisemann, Cloninger, 1998; Fresán, Apiquian, Nicolini ve Cervantes, 2007).

$\mathrm{Bu}$ araştırmada, diğer öğrencilerle olan ilişkilerinde zorba, zorbalıktan kaçınan ve kendine güvenen tutumlar sergileyen öğrencilerin iş birliği yapma karakter özelliği açısından değerlendirilmesi amaçlanmıştır. Bu amaçla ilişkilerinde farklı tutumlara sahip olan öğrenciler iş birliği yapma karakter özelliğinin alt boyutları açısından karşılaştırılmıştır. Zorba, zorbalıktan kaçınan ve kendine güvenen tutumlar ile iş birliği yapma karakter özelliğinin cinsiyet ve sınıf düzeyi değişkenlerine bağlı olarak farklılaşıp farklılaşmadığı da belirlenmeye çalışılmıştır.

\section{YÖNTEM}

\section{Örneklem}

Araştırma, Ankara ilinde lise öğrenimini sürdüren toplam 690 öğrenci ile yapılmıştır. Araştırma, öğrencilerinin çoğunluğunu alt ve orta sosyoekonomik düzey ailelerin çocuklarının oluşturduğu toplam üç lisede yürütülmüştür. Çalışmaya katılan öğrencilerin yaşları 15 ile 19 arasında değişmektedir. Örneklemi oluşturan öğrencilerin 376's1 kız (\%54.5), 314'ü erkektir (\%45.5). Öğrencilerin sınıf düzeylerine göre dağılımına bakıldığında; 236 (34.2) öğrencinin dokuzuncu sinıfa, 258 (\%37.4) öğrencinin onuncu sinıfa ve 196 (\%28.4) öğrencinin de on birinci sinıfa devam ettikleri görülmektedir.

\section{Ölçme Araçları}

Mizaç ve Karakter Envanteri (TCI): Mizaç ve karakter envanteri, Cloninger'in kişiliğin iki temel bileşeni olan mizaç ve karakterdeki normal 
ve anormal değişimleri açıklayan psikobiyolojik kişilik modeline dayalı olarak geliştirilmiş bir ölçektir (Köse ve diğer., 2004). Mizaç ve Karakter Envanteri dördü mizaç (yenilik arayışı, zarardan kaçınma, ödül bağımlılığı, sebat etme) ve üçü karakter (kendini yönetme, iş birliği yapma, kendini aşma) olmak üzere kişiliğin yedi temel boyutunu ölçmeye yaramaktadır. Ölçeğin Türk evrenine uyarlaması Köse ve diğerleri (2004) tarafından yapılmıştır. Ölçek "Doğru" ya da "Yanlış" şeklinde yanıtlanan 240 maddeden oluşmaktadır.

Mizaç ve Karakter Envanteri’nin “İş Birliği Yapma” karakter özelliği, sosyal kabul, empati, yararlılık, sevecenlik ve erdemli-vicdanlı olma özelliklerini içerir. Model, iş birliği yapan insanların hoşgörülü, empati yeteneği olan, yararlı, sevecen ve erdemli olduklarını ileri sürer. Mizaç ve Karakter Envanteri, karakter alt boyutunda yer alan "İş Birliği Yapma (Cooperativeness)" beş alt ölçekten (sosyal kabul - sosyal hoşgörüsüzlük; empati - sosyal ilgisizlik; yardım severlik - yardım sevmemezlik; acıma inkitamc1lık; temiz kalplilik vicdanlılık-kendi kendine yarar sağlama) ve 42 maddeden oluşmaktadır. Alt ölçeklerden alınan yüksek puanlar ölçeğin adında belirtilen ilk özelliğin yüksekliğine, düşük puanlar ise ikinci özelliğin yüksekliğine işaret etmektedir.

Mizaç ve Karakter Envanteri'nin Köse ve diğerleri (2004) tarafından 683 denek üzerinde yapılan geçerlik ve güvenirlik çalışmalarında, ölçeğin iç tutarlılık Cronbach Alpa katsayısı mizaç boyutunda .60 ile .85, karakter boyutunda .82 ile .83 arasında hesaplanmıştır. Ölçeğin faktör yapısını irdeleyebilmek için önce, yedi-faktörlü çözüme için Kaiser normalizasyonlu oblimin dönüştürmesine göre temel eksen faktör analizi uygulanmıştır. Sonrasında faktör yapısı varimax dönüştürmesine göre temel bileşenler faktör analizi ile incelenmiştir.

Öğrenci İlişkileri Tutum Ölçeği: Öğrenci İlişkileri Tutum Ölçeği öğrencilerin diğer öğrencilerle olan ilişkilerindeki üç tutum boyutunu (zorba, kendine güvenen ve zorbalıktan kaçınan) belirlemeyi amaçlayan bir ölçektir ve Koç (2006) tarafindan geliştirilmiştir. Ölçek, 15'i olumlu ve 6'sı olumsuz olmak üzere 5'li likert tipinde toplam 21 maddeden oluşmaktadır.

Ölçekte yer alan 10 madde zorba, 6 madde güvenli, 5 madde zorbalıktan kaçınan tutum boyutlarını belirlemeye yöneliktir. Ölçekte her tutum boyutu (alt ölçek) için farklı bir puan hesaplandığından alt ölçeklerden alınabilecek en yüksek ve en düşük puanlar alt ölçeklere göre değişmektedir. Zorba tutum alt ölçeğinde alınabilecek en yüksek puan 50, en düşük puan 10 'dur. $\mathrm{Bu}$ alt ölçekten alınan puanın yüksek olması, kişinin kendisini saldırgan ve zorba tutuma sahip bir birey olarak algıladığını göstermektedir. 
Kendine güvenen tutum alt ölçeğinden alınabilecek en yüksek puan 30 ve en düşük puan 6'dır. Bu alt ölçekten alınan puanın yükssek olması, kişinin kendisini kişilerarası ilişkilerde kendine güvenen bir tutuma sahip bir birey olarak algıladığını göstermektedir. Zorbalıktan kaçınan tutum alt boyutundan alınabilecek en yüksek puan 25 , en düşük puan 5'tir. Bu alt ölçekten alınan puanın yüksek olması, kişinin kendisini bir zorba gibi davranmaktan kaçınan bir tutuma sahip bir birey olarak algıladığını göstermektedir.

Ölçeğin geçerliği için Saldırganlık Envanteri puanları ile Öğrenci İlişkileri Tutum Ölçeği puanları arasındaki korelasyonlara bakılmıştır. Saldırganlık Envanteri puanları ile hesaplanan korelasyon katsayıları sırasıyla zorba tutum alt ölçeği için .60, güvenli tutum alt ölçeği için .41 ve kaçınan tutum alt ölçeği için .67 olarak bulunmuştur. Temel bileşenler faktör analizi uygulaması sonunda, ölçeğin üç faktörlü bir ölçek olduğu ve ölçeği oluşturan 21 maddenin .51 ile .75 arasında faktör yük değerlerine sahip oldukları görülmüştür. Ölçeğin güvenirlik çalışması için hesaplanan alfa katsayıları zorba tutum alt ölçeği için .86, kendine güvenen tutum alt ölçeği için .69 ve zorbalıktan kaçınan tutum alt ölçeği için .57'dir. Ölçeğin her bir faktörünün açıkladığı varyanslara bakıldığında, zorba tutum alt boyutunun varyansin \%22'sini, kendine güvenen tutum alt boyutunun varyansin $\% 12$ 'sini ve zorbalıktan kaçınan tutum alt boyutunun varyansın \%9'unu açıkladığı görülmüştür. Tüm alt boyutların açıkladığı toplam varyans \%43’tür (Koç, 2006).

\section{BULGULAR}

Lise öğrencilerinin Öğrenci İlişkileri Tutum ölçeği (zorba-kaçınangüvenli) puanlarının cinsiyete bağlı anlamlı bir farklılık gösterip göstermediği belirlenmeye çalışılmıştır. t-testi sonuçlarına göre, zorba [ $\mathrm{t}_{(688)}$ $=6.14, \mathrm{p}<.01]$ ve zorbalıktan kaçınan $\left[\mathrm{t}_{(688)}=4.94, \mathrm{p}<.01\right]$ tutumlar cinsiyete bağlı anlamlı bir farklılık gösterirken; kendine güvenen tutum $\left[\mathrm{t}_{(688)}=.90, \mathrm{p}>.05\right]$ cinsiyete bağlı anlamlı bir farkl111k göstermemektedir. Zorba tutumu açısından bakıldığında, erkek öğrencilerin ortalamalarının $(\bar{x}=27.04) \mathrm{kız}$ öğrencilerin ortalamalarından $(\bar{x}=24.59)$ daha yüksek olduğu görülmektedir. Aynı fark zorbalıktan kaçınan tutum açısından da görülmektedir. Zorbalıktan kaçınan tutum açısından erkek öğrencilerin ortalamaları ( $\bar{x}=11.56) \mathrm{kız}$ öğrencilerin ortalamalarından $\quad(\bar{x}=10.07)$ daha yüksektir. Bu sonuçlara göre, erkekler daha fazla zorba ve zorbalıktan kaçınan tutum sergilemektedir. 
Lise öğrencilerinin iş birliği yapma toplam puanlarının cinsiyete bağlı anlamlı bir farklılık gösterip göstermediği belirlenmeye çalışılmıştır. t-testi sonuçlarına göre, iş birliği yapma toplam puanı cinsiyete bağlı anlamlı bir farklılaşma göstermektedir $\left[\mathrm{t}_{(688)}=4.34, \mathrm{p}<.01\right]$. Kız öğrencilerin iş birliği yapma toplam puan ortalaması $(\bar{x}=27.63)$ erkek öğrencilerin puan ortalamasından ( $\bar{x}=25.44$ ) daha yüksektir. Bu sonuçlara göre, kız öğrenciler erkek öğrencilerden daha fazla iş birliği yapma karakter özelliği sergilemektedir.

Öğrenci İlişkileri Tutum Ölçeği puanlarının sınıf düzeyleri açısından farklılaşıp farklılaşmadığını gösteren ANOVA sonuçlarına göre, zorba $\left[\mathrm{F}_{(2-687)}=2.48, \mathrm{p}>.05\right]$, zorbaliktan kaçinan $\left[\mathrm{F}_{(2-687)}=1.26, \mathrm{p}>.05\right]$, ve kendine güvenen $\left[\mathrm{F}_{(2-687)}=.39, \mathrm{p}>.05\right]$ tutum puanlarında sinıf düzeyleri açısından anlamlı bir farklılaşma yoktur. Buna göre, öğrenci ilişkilerinde sahip olunan zorba, zorbalıktan kaçınan ve kendine güvenen tutumları sınıf düzeylerine bağlı anlamlı bir farklılaşma göstermemektedir.

İş birliği yapma karakter özelliği toplam puanlarının sınıf düzeyleri açısından farklılaşıp farklılaşmadığını gösteren ANOVA sonuçlarına göre, iş birliği yapma karakter özelliği toplam puanlarında $\left[\mathrm{F}_{(2-687)}=.47, \mathrm{p}>.05\right]$ sınıf düzeyleri açısından anlamlı bir farklılaşma yoktur. Bu sonuçlara göre, iş birliği yapma karakter özelliği sınıf düzeylerine bağlı anlamlı bir farklılaşma göstermemektedir.

Öğrenci İlişkileri Tutum Ölçeği puanlarının iş birliği yapma karakter özelliğinin toplam puanı ve alt boyutları ile ilişkisini belirlemek amacıyla yapılan Pearson Momentler Çarpımı Korelasyon Analizi sonuçları Tablo1 'de sunulmuştur.

Tablo-1'de görüldüğü gibi, zorba ve zorbalıktan kaçınan tutum puanları ile iş birliği yapma karakter özelliği toplam puanları arasında negatif yönde ve anlamlı bir ilişki vardır. Bu ilişki zorba tutum puanı için düşük düzeyde $(\mathrm{r}=-0.141, \mathrm{p}<.01)$ iken; zorbalıktan kaçınan tutum puanı için orta düzeydedir $(\mathrm{r}=-0.309, \mathrm{p}<.01)$. Kendine güvenen tutum puanı ile iş birliği yapma karakter özelliği toplam puanı arasında düşük düzeyde, negatif yönde ve anlamlı bir ilişki vardır $(\mathrm{r}=0.174, \mathrm{p}<.01)$. Bu bulgulardan hareketle, iş birliği yapma toplam puanı artıkça zorba ve zorbalıktan kaçınma tutum puanlarının azaldığı, kendine güvenen tutum puanının ise arttı̆̆ 1 söylenebilir. 


\section{TABLO-1}

\section{Öğrenci İlişkileri Tutum Ölçeği Puanlarının İş Birliği Yapma Karakter Özelliğinin}

Toplam Puanı ve Alt Boyutlanı ile İlişkisi

\begin{tabular}{|c|c|c|c|}
\hline $\begin{array}{l}\text { İş Birliği Yapma Karakter } \\
\text { Özellikleri }\end{array}$ & Zorba & $\begin{array}{l}\text { Kendine } \\
\text { Güvenen }\end{array}$ & $\begin{array}{l}\text { Zorbalıktan } \\
\text { Kaçınan }\end{array}$ \\
\hline $\begin{array}{l}\text { Sosyal Kabul - Sosyal } \\
\text { Hoşgörüsüzlük }\end{array}$ & $-.136 * *$ & $.108 * *$ & $-.241 * *$ \\
\hline Empati - Sosyal İlgisizlik & -.041 & .063 & $-.138 * *$ \\
\hline $\begin{array}{l}\text { Yardım Severlik -Yardım } \\
\text { Sevmemezlik }\end{array}$ & -.068 & $.090 *$ & $-.125 * *$ \\
\hline Acıma - İntikamcılık & -.072 & $.199 * *$ & $-.232 * *$ \\
\hline $\begin{array}{l}\text { Temiz Kalplilik Vicdanlılık- } \\
\text { Kendi Kendine yarar Sağlama }\end{array}$ & $-.168 * *$ & $.082 *$ & $-.294 * *$ \\
\hline İş Birliği Toplam Puanı & $-.141 * *$ & $.174 * *$ & $-.309 * *$ \\
\hline
\end{tabular}

Tablo-1'de görüldüğü gibi, zorba tutum puanları ile iş birliği yapma karakter özelliği alt boyutlarından sosyal kabul-sosyal hoşgörüsüzlük ( $\mathrm{r}=$ $0.136, \mathrm{p}<.01)$ ve temiz kalplilik vicdanl1lik-kendi kendine yarar sağlama $(\mathrm{r}=$ $-0.168, \mathrm{p}<.01)$ boyutları arasında düşük düzeyde, negatif yönde ve anlamlı bir ilişki vardır. Buna göre, iş birliği yapma karakter özelliğinin alt boyutlarından sosyal kabul ve temiz kalplilik vicdanlılık puanları artıkça zorba tutumun azaldığı söylenebilir.

Tablo-1'deki korelasyon analizi sonuçları kendine güvenen tutum puanları ile iş birliği yapma karakter özelliği alt boyutlarından sosyal kabulsosyal hoşgörüsüzlük $(\mathrm{r}=0.108, \quad \mathrm{p}<.01), \quad$ yardım $\quad$ severlik-yardım sevmemezlik $(\mathrm{r}=0.090, \mathrm{p}<.05)$, acima-intikamcilik $(\mathrm{r}=0.199, \mathrm{p}<.01)$ ve temiz kalplilik vicdanlılık-kendi kendine yarar sağlama $(\mathrm{r}=0.082, \mathrm{p}<.05)$ boyutları arasında düşük düzeyde, pozitif yönde ve anlamlı bir ilişki olduğunu göstermektedir. $\mathrm{Bu}$ bulgulardan hareketle, iş birliği yapma karakter özelliği alt boyutlarından empati-sosyal ilgisizlik boyutu hariç olmak üzere, tüm alt boyutlardaki puanlar artıkça kendine güvenen tutumun arttığı söylenebilir.

Yine Tablo-1'de görüldüğ̈̈ gibi, zorbalıktan kaçınan tutum puanları ile iş birliği yapma karakter özelliği alt boyutlarından sosyal kabul-sosyal 
hoşgörüsüzlük ( $\mathrm{r}=-0.241, \mathrm{p}<.01)$, empati-sosyal ilgisizlik $(\mathrm{r}=-0.138, \mathrm{p}<.01)$, yardım severlik-yardım sevmemezlik $(\mathrm{r}=-0.125, \mathrm{p}<.01)$, acıma-intikamcılık $(\mathrm{r}=-0.232, \mathrm{p}<.01)$ ve temiz kalplilik vicdanlılık-kendi kendine yarar sağlama $(\mathrm{r}=-0.294, \mathrm{p}<.01)$ boyutları arasında düşük düzeyde, negatif yönde ve anlamlı bir ilişki olduğunu göstermektedir. Bu sonuçlara göre, iş birliği yapma karakter özelliğinin tüm alt boyutlarındaki puanlar artıkça zorbalıktan kaçınan tutumun azaldığı söylenebilir.

\section{TARTIŞMA ve ÖNERILLER}

$\mathrm{Bu}$ çalışmadan elde edilen bulgulara göre, cinsiyet zorba ve kaçınan tutum sergilemede anlamlı bir farklılaşmaya neden olmaktadır ve erkekler daha fazla zorba ve zorbalıktan kaçınan tutum sergilemektedir. Alanyazında cinsiyetin saldırganlığın en önemli belirleyicilerinden biri olduğunu (Swam ve diğer., 2006); erkek öğrencilerin kız öğrencilerden anlamlı bir biçimde daha fazla zorba ve zorba/kurban olduğunu (Parada, 2006; Yang ve diğer., 2005) ortaya koyan araştırma bulguları vardır. $\mathrm{Bu}$ araştırmada öğrencilerin diğer öğrencilerle ilişkilerinde sergiledikleri tutumların cinsiyete bağlı olarak gösterdiği farklılık alanyazın bulguları ile paralellik göstermektedir.

$\mathrm{Bu}$ araştırmada cinsiyet iş birliği yapma karakter özelliğinde anlamlı bir farklılaşmaya neden olmaktadır ve kız öğrenciler erkek öğrencilerden daha fazla iş birliği yapma karakter özelliği sergilemektedir. Bu bulgu erkek öğrencilerin kız öğrencilerden daha fazla zorba ve zorbalıktan kaçınma tutumu sergiledikleri bulguları ile birlikte değerlendirildiğinde, kızların daha fazla iş birliği yapıyor olmalarının onların diğer öğrencilerle olan ilişkilerinde erkeklere oranla daha az zorba ve zorbalıktan kaçınan tutum sergilemelerinde rolü olduğu düşünülebilir.

$\mathrm{Bu}$ çalışmada öğrencilerin diğer öğrencilerle olan ilişkilerinde sergiledikleri tutumların (zorba, zorbalıktan kaçınan ve kendine güvenen) ve iş birliği yapma karakter özelliği toplam puanlarının sınıf düzeylerine bağlı olarak farklılaşmadığ 1 ortaya konulmuştur. $\mathrm{Bu}$ bulgular öğrenci ilişkilerindeki tutumların ve iş birliği yapma özelliğinin cinsiyete bağlı farklılaşması ile birlikte değerlendirildiğinde, öğrencilerin iş birliği yapma karakter özelliğinde sınıf düzeylerine bağlı bir farklılaşma olmamasının ilişkilerinde sergiledikleri tutumların da sınıf düzeylerine bağlı olarak değişiklik göstermemesinde rolü olduğu söylenebilir.

$\mathrm{Bu}$ çalışmada, öğrencilerin diğer öğrencilerle olan ilişkilerinde sergiledikleri zorba ve zorbalıktan kaçınma tutum puanları ile iş birliği yapma karakter özelliği toplam puanları arasında negatif yönde anlamlı ilişkiler olduğu; kendine güvenen tutum puanları ile iş birliği yapma karakter özelliği toplam puanları arasında pozitif yönde anlamlı ilişkiler olduğu 
belirlenmiştir. Bu bulgular zorba tutum kadar zorbalıktan kaçınan tutumun da iş birliği yapma karakter özelliği ile bağdaşmayan bir tutum olduğuna işaret etmektedir. Bu bulgulara göre, iş birliği yapma karakter özelliğinin tüm alt boyutlarında olumsuz karakter özelliklerine sahip olan ergenlerin daha fazla kaçınan tutum geliştirdikleri görülmektedir. Zorbalıktan kaçınan tutum gösterenlerin ya zorbalığa maruz kalan kişiler oldukları ya da zorbalığın potansiyel hedefleri arasında oldukları hatırlanırsa, bunları zorbalığın kurbanları ya da potansiyel kurbanları olarak görmek yanlış olmayacaktır. Swearer, Grills, Haye ve Cary'nin (2004) aktardıklarına göre, alayazındaki bazı çalışmalarda kurbanlar pasif ve proaktif kurbanlar olarak iki farklı türde tanımlanmakla birlikte, kurbanların özellikleriyle ilgili araştırma bulguları, kurbanların düşük benlik saygısına, kendilerine zorbaca davranan kişilerden bile daha düşük öz değer duygusuna sahip olduklarını; sosyal olarak içe dönük olduklarını ve arkadaşlarına katılmadıklarını; kaygılı, güvensiz ve intikamcı olduklarını; arkadaşları tarafından sevilmediklerini ve uyum sorunları yaşamaya yatkın olduklarını ortaya koymaktadır. Flannery (2006), kurbanların başkalarıyla etkileşimlerinde güvensiz, kaygılı ve pasif olduklarını ve yalnızlı̆̆ sevdiklerini ifade etmektedir. Kurban özellikleriyle ilgili alayazındaki araştırma bulgularıyla birlikte düşünüldügünde, zorbalıktan kaçınan tutumun sosyal hoşgörüsüz, sosyal ilgisiz, intikamcı, kendi kendine yarar sağlayan ve yardım sevmez karakter özelliklerine sahip öğrencilerce daha çok sergilenmesini anlamak çok daha kolaylaşmaktadır.

Öğrenci ilişkilerinde sergilenen tutumlar ile iş birliği yapma karakter özelliği arasındaki ilişkiler iş birliği yapma karakter özelliğinin alt boyutları açısından ele alındığında, zorba tutumun sosyal kabullenme-sosyal hoşgörüsüzlük ve temiz kalplilik vicdanlılık-kendi kendine yarar sağlama alt boyutları ile negatif yönde ve anlamlı ilişkiler gösterdiği görülmüştür. Yani bir öğrencinin sosyal kabullenme ve temiz kalplilik vicdanlılık özellikleri geliştikçe daha az zorbalık tutumu sergilediği düşünülebilir.

Kendine güvenen tutumun iş birliği yapma karakter özelliğinin empatisosyal ilgisizlik alt boyutu hariç olmak üzere, diğer dört alt boyut ile (sosyal kabul-sosyal hoşgörüsüzlük, yardım severlik-yardım sevmemezlik, acımaintikamcilık ve temiz kalplilik vicdanl1l1k-kendi kendine yarar sağlama) pozitif yönde ve anlamlı ilişkiler gösterdiği belirlenmiştir. Bu bulgulardan hereketle, bir öğrencinin sosyal kabul, yardım severlik, acıma ve temiz kalplilik vicdanlılık özellikleri geliştikçe daha fazla kendine güvenen tutum sergilediği düşünülebilir. O’Moore ve diğerlerinin (1997) İrlanda okullarında zorbalığı inceledikleri çalışmaları, hiç zorbalık yapmamış ya da hiç zorbalığa maruz kalmamış çocuk ve ergenlerin zorbalık yapan veya zorbalığa maruz 
kalan çocuk ve ergenlerden daha yüksek özsaygı düzeyine sahip olduklarını ortaya koymuştur (Akt. O'Moore, 2002). Zorbalık yapmamış ya da zorbalığa maruz kalmamış olan kişiler ilişkilerinde kendine güvenen tutum geliştiren kişilerdir. Özsaygının yüksek olması, kişinin sahip olduğu özelliklere karşı olumlu bir tutum içinde olduğunu gösterir. İlişkilerinde kendine güvenen tutum geliştirenlerinlerin sahip oldukları olumlu karakter özelliklerinden dolayı gerçekten yüksek özsaygı düzeyine sahip olmaları mantığa uygun görünmektedir.

Zorbalıktan kaçınan tutumun iş birliği yapma karakter özelliğinin tüm alt boyutları ile (sosyal kabul-sosyal hoşgörüsüzlük, empati-sosyal ilgisizlik, yardım severlik-yardım sevmemezlik, acıma-intikamcılık ve temiz kalplilik vicdanlıl1k-kendi kendine yarar sağlama) negatif yönde ve anlamlı ilişkiler gösterdiği belirlenmiştir. Bu bulgulara göre bir öğrencinin sosyal kabul, empati, yardım severlik, acıma ve temiz kalplilik vicdanlılık özellikleri geliştikçe daha az zorbalıktan kaçınan tutum sergilediği söylenebilir. $\mathrm{Bu}$ bulgular yukarıda özetlenen alanyazındaki kaçınan tutum sergileyen kişilerle ilgili tanım ve bulgularla paralellik göstermektedir.

Alanyazındaki bazı çalışmalarda öğrenci ilişkilerinde sergilenen tutumlar ile iş birliği yapma karakter özelliği arasındaki ilişkilere yönelik yukarıda ifade edilen bulguları doğrudan ya da dolaylı bir biçimde destekleyen bulgular yer almaktadır. Fitzgerald (1999), düşük öz-değer duygusuna sahip olan bazı kişilerin kendilerini başarısız algılama eğilimi içinde olduklarını, bunun da onların başkalarına karşı öfke duymalarına neden olduğunu ve güçlü hissetmek için başkalarına güç kullanmaya ittiğini belirtmektedir. Zorbaların kendilerinden daha başarılı ya da daha popüler olan çocuklara karşı daha kıskanç olabildiğini ve bu nedenle yaşamın kendilerine karşı adil olmadığını düşünebildiğini ifade eden Fitzgerald'a göre, zorbalar başkalarının başarılarından rahatsızlık duyabildikleri için toplumsal ilişkilerinde de kayıptadır. Araştırmacı, kendini güvende hissetmeyen bazı zorbaların başkalarını küçümseme ve incitme davranışlarını sergilediğini belirtirken, zorbaların paylaşmayı bilememe, bir grubun üyesi olamama, oyunda kaybetmeye tahammül edememe gibi özellikler de gösterebildiğini eklemektedir. Camodeca ve Goosens'in (2005) araştırma bulgularına göre, diğer çocuklarla karşılaştırıldığında zorba ve kurbanlar daha fazla düşmanca yorum yapmakta, daha fazla öfke yaşamakta, daha fazla intikam almakta ve daha kolay saldırmaktadır. Zorba ve kurban özelliklerine dair yukarıda özetlenen araştırma bulguları dikkate alındığında, bu araştırmada elde edilen ve sosyal hoşgörüsüz ve kendi kendine yarar sağlama karakter özelliği baskın olan öğrencilerin daha fazla zorba tutum sergilemeleri doğal görünmektedir. 
$\mathrm{Bu}$ çalışmada zorba tutum ve kendine güvenen tutum ile iş birliği yapma karakter özelliğinin empati-sosyal ilgisizlik alt boyutu arasinda anlamlı bir ilişki olmadığ belirlenmiştir. Alanyazında zorba tutum ve empati arasındaki ilişkiyi doğrudan ele alan ilk çalışma Endresen ve Olweus (2001) tarafindan yapılmıştır. Bu çalışmada, empatik tepki verme ile zorbalık yapma arasında negatif yönde ve düşük bir korelasyon bulunmuştur. Espelage, Mebane ve Adams'ın (2004) araştırma bulguları empatinin kızlar açısından hem zorbalığı hem de kavga etme davranışını azaltma eğilimi gösterdiğini; fakat erkeklerin fiziksel saldırganlıklarını azaltmada daha az önemli olduğunu ortaya koymuştur. Elliott (2002), kronik zorbaların özelliklerini sıralarken, bu tür zorbaların kurbanlara karşı empati kazandırmayı amaçlayan yaklaşımlara yanıt vermediğini belirtmektedir. Elliott, bu tip zorbaların davranışlarını manipule etmede çok yetenekli olduğunu ve gerektiğinde (örneğin öğretmenlere zorba olmadığı mesajını vermeye çalışırken) kurbanlara karşı sempatik duygular besliyormuş gibi görünebildiğini ifade etmektedir. Frey de (2005), toplumsal yetenekleri itibariyle daha donanımlı olan zorbaların zorba davranışlarını gizlilik içinde sürdürmede daha ustaca davrandığını belirlemiştir. Bu araştırmada elde edilen ve iş birliği yapma karakter özelliğinin empati alt boyutu ile zorba ve kendine güvenen tutumlar arasında anlamlı bir ilişkinin olmadığ biçimindeki bulgu, empati ve zorbalık arasındaki ilişkiyi belirlemeye yönelik yukarıda özetlenen alanyazın bulgularıyla birlikte değerlendirildiğinde, bu karakter özelliğinin zorba tutumları belirlemede ve azaltmada iş birliği yapmanın diğer alt boyutlarına oranla daha az önemli olduğu söylenebilir.

\section{SONUC}

Öğrenci ilişkilerinde sergilenen tutumlar ile iş birliği yapma karakter özelliği arasındaki ilişkinin incelendiği bu araştırma çerçevesinde elde edilen sonuçlar şu şekilde özetlenebilir: Cinsiyet öğrenci ilişkilerinde sergilenen tutumlar (zorba, zorbalıktan kaçınan ve kendine güvenen) ve iş birliği yapma karakter özelliği açısından önemli bir değişkendir. Erkeklerin daha fazla zorba ve kaçınan tutum sergilerken kızlar daha fazla iş birliği yapma karakter özelliği göstermektedir. Öğrenci ilişkilerinde sergilenen tutumlar ve iş birliği yapma karakter özelliği sınıf düzeyine bağlı bir farklılaşma göstermemektedir. Zorba, zorbalıktan kaçınan ve kendine güvenen tutumlar iş birliği yapma karakter özelliği ile anlamlı ilişkiler göstermektedir. Zorba ve zorbalıktan kaçınan tutum sergileyen öğrenciler iş birliği yapma karakter özelliği açısından benzerlik göstermektedir.

Alanyazında arkadaşlara sahip olmak ve başkaları tarafindan hoşlanılmanın kurban olmaya karşı koruyucu faktörler olduğuna (Pellegrini, Bartini ve Brooks, 1999) ve karakter eğitiminin öğrencilerin toplumsal 
ilişkilerdeki yeterliklerini arttırdığına dair (Miller ve diğer., 2005) araştırma bulguları vardır. $\mathrm{Bu}$ araştırmanın orta koyduğu bulgular, yukarıda sözü edilen araştırma bulguları ile birlikte düşünüldüğünde, okul zorbalığ konusunda yapılacak daha sonraki araştırmalar için şu önerilerde bulunulabilir:

Zorba ve zorbalıktan kaçınan tutumlar iş birliği yapma karakter özellikleri açısından benzerlik gösterdiğinden, okullarda şiddet ve saldırganlığı azaltmaya yönelik programlar sadece zorba tutum sergileyen öğrencileri değil, zorbalıktan kaçınan tutum sergileyen öğrencileri de kapsamalıdır. Cloninger'in kişilik modelinde yer alan diğer karakter özellikleri ile tutumlar arasındaki ilişkilerin ortaya konulacağ 1 çalışmalar yapılmalıdır. İş birliği yapma karakter özelliğini geliştirmeyi amaçlayan eğitim programları hazırlanıp etkililikleri uygulamalarla sınanmalıdır.

\section{KAYNAKÇA}

Camodeca, M. and Goosens, F.A. (2005). Aggression, social cognition, anger and sadness in bullies and victims. Journal of Child Psychology and Psychiatry, 46, (2), 186-197.

Casey, J. (2004). Using the school curriculum to support violence reduction. Children and violence: Europe and violence in schools-how to make a difference. Council of Europe. pp. 53-68.

Cloninger, C. (1987). A systematic method for clinical description and classification of personality variants. A proposal. Arch. Gen. Psychiatry, $44,573-588$.

Cowie, H. (2004). Developing pupil-led strategies to reduce violence in schools. Children and violence: Europe and violence in schools-how to make a difference. Council of Europe. pp. 69-80.

Çınkır, Ş. ve Karaman-Kepenekçi, Y. (2003). Öğrenciler arası zorbalık. Eğitim yönetimi. Bahar 2003: Ankara..

Derosier, M.E. and Marcus, S.R. (2005). Building friendships and combating bullying: Effectiveness of SSGRIN at one year follow up. Journal of Clinical Child and Adolescent Psychology, 34, (1), 140-150.

Durmuş, E. ve Gürgan, U. (2005). Lise öğrencilerinin şiddet ve saldırganlık eğilimleri. Türk Eğitim Bilimleri dergisi, 3, (3), 253-269. Ankara.

Elliott, M. (2002). Bullies and victims. In M.Elliott (Ed.), A practical guide to coping for schools: Bullying (3rd ed., pp.1-11). Great Britain: Pearson Education Limited.

Endresen, I.M. and Olweus, D. (2001). Self-reported empathy in Norwegian adolescents: Sex differences, age trends, and relationship to bullying. In A.C. Bohart, C. Arthur, and D.J. Stipek (Eds.), Constructive \& destructive 
behavior: Implications for family, school \& society (pp. 147-165). Washington, D.C.: American Psychological Association.

Espelage, D.L. and Swearer, S.M. (2003). Research on school bullying and victimization: What have we learned and where do we go from here? School Psychological Review, 32, (3), 365-383.

Espelage, D.L., Mebane, S.E. and Adams, R.S. (2004). Empati, caring, and bullying: Toward an understanding of complex associations. In D.L. Espelage, S.M. Swearer (Eds.), Bullying in American schools: A socialecological perspective on prevention and intervention (pp. 37-61). New Jersey: Lawrence Erlbaum Associates, Publishers.

Fitzgerald, D. (1999). Bullying in our schools: Understanding and tackling bullying. Dublin: Blackhall Publishing.

Flannery, D.J. (2006). Violence and mental health in everyday life: Prevention and intervention strategies for children and adolescents. New York: AltaMira Press.

Fonagy, P., Twemlow, S.W., Vernberg, E., Sacco, F.C. and Little, T.D. (2005). Creating peaceful school learning environment: The impact of an antibullying programme on educational attainment in elementary schools. Medical Science Monitor, 11, (7), 317-325.

Fresán, A., Apiquian, R., Nicolini, H. and Cervantes, J.J. (2007). Temperament and character in violent schizophrenic patients. Schizophrenia Research, $94,74-80$.

Frey, S. (2005). Gathering and communicating information about school bullying: Overcoming secrets and lies. Health Education, 105, (6), 409413.

Galvin, P. (2004). The rol of a school audit in preventing and minimising violence. Children and violence: Europe and violence in schools-how to make a difference. Council of Europe. pp. 23-39.

Horne, A.M., Orpinas, P., Newman-Carlson, D. and Bartolomucci, C.L. (2004). Elementary school bully busters program: Understanding why children bully and what to do about it. In D.L. Espelage, S.M. Swearer (Eds.), Bullying in American schools: A social-ecological perspective on prevention and intervention (pp. 297-325). New Jersey: Lawrence Erlbaum Associates, Publishers.

Koç, Z. (2006). Lise öğrencilerinin zorbalık düzeylerinin yordanması. Yayınlanmamış doktora tezi. Gazi üniversitesi Eğitim Bilimleri Enstitüsü: Ankara.

Köse, S., Sayar, K., Ak, İ., Aydın, N., Kalelioğlu, Ü., Kırkpınar, İ., Reeves, R.A., Przybeck, T.R. ve Cloninger, C.R. (2004). Mizaç ve Karakter Envanteri (Türkçe TCI): Geçerlik, Güvenirliği ve Faktör Yapısı. Klinik Psikofarmakoloji Bülteni, 14, (3), 107-131.

Limber, S.P. (2004). Implementation of the olweus bullying prevention program in American schools. In D.L. Espelage, S.M. Swearer (Eds.), Bullying in 
American schools: A social-ecological perspective on prevention and intervention (pp. 351-363). New Jersey: Lawrence Erlbaum Associates, Publishers.

Miller, T.W., Kraus, R.F. and Veltkamp, L.J. (2005). Character education as a prevention strategy in school-related violence. The Journal of Primary Prevention, 26, (5), 455-466.

Nagoshi, C., Walter, D., Muntaner, C. and Haertzen, C.A. (1992). Validation of the Tridimensional Personality Questionnaire in a sample of male drug users. Pers. Individ. Differ. 13, 401-409.

O'Moore, A.M. (2002). Teachers hold the key to change. In M.Elliott (Ed.), $A$ practical guide to coping for schools: Bullying (3rd ed., pp.154-179). Great Britain: Pearson Education Limited.

O'Moore, M. and Minton, S.J. (2004). Making the school environment safe. Children and violence: Europe and violence in schools-how to make a difference. Council of Europe. pp. 81-95.

Olweus, D. (1993). Bullying at school: What we know and what we can do. Oxford, England: Blackwell Press.

Olweus, D. (1999). The nature of school bullying; a cross national perspective. London and New York: Routledge.

Olweus, D. (2005). A useful evaluation design, and effects of the Olweus bullying prevention programme. Psychology, Crime and Law, 11, (4), 389402.

Öğülmüş, S. (1995a). Okullarda (Liselerde) şiddet ve saldırganlık, Yayınlanmamış Araştırma Raporu. A.Ü.Eğitim Bilimleri Fakültesi.

Öğülmüş, S. (1995b). Liselerdeki şiddet ve saldırganlık olaylarının psikolojik temelleri. Orta Öğretimde Yeniden Yapılandırma. 6. Milli Eğitim Sempozyumu. Türk Yurdu Yayınları.

Parada, R.H. (2006). School Bullying: Psychosocial Determinants and Effective Intervention. A doctoral thesis submitted to the University of Western Sydney: Greater Western Sydney.

Pekel-Uludağlı, N. ve Uçanok, Z. (2005), Akran zorbalığı gruplarında yalnızlık ve akademik başarı ile sosyometrik statüye göre zorba/kurban davranış türleri. Türk psikoloji dergisi, 20(56).s.77-92.

Pellegrini, A.D., Bartini, M. and Brooks, F. (1999). School bullies, victims, and aggressive victims: Factors relating to group affiliation and victimization in early adolescence. Journal of Educational Psychology, 91, (2), 216-224.

Pietzak, D., Petersen, G.J. and Speaker, K.M. (1998). Perception of school violence by elementary and middle school personel. Professional School Counseling, 1, (4), 23-29.

Pişkin, M. ve Ayas, T. (2005) Akranlarına zorbalık yapan (zorba) ve zorbalığa uğrayan (kurban) lise öğrencilerinin "içedönüklük-dışadönüklük", "utangaçlık" ve "özsaygı" değişkenleri bakımından incelenmesi. VIII. 
Psikolojik danışma ve rehberlik kongresi. Marmara Üniversitesi Atatürk Eğitim Fakültesi. İstanbul.

Pişkin, M. (2006). Akran zorbalığı olgusunun ilköğretim öğrencileri arasındaki yaygınlığının incelenmesi I. Şiddet ve Okul: Okul ve çevresinde çocuğa yönelik şiddet ve alınabilecek tedbirler sempozyumu bildiri özeti. İstanbul.

Ruchkin, V., Eisemann, M. and Cloninger, C. (1998). Behaviour/emotional problems in male juvenile delinquents and controls in Russia: The role of personality traits. Acta Psychiatr. Scand. 98, 231-236.

Salmivalli, L., Kaukiainer, A. and Voeten, M. (2005). Anti bullying intervention. Implementation and outcoma. British journal of educational psychology; 75 (3), 465-487.

Shaughnessy, J. (2004). Creating a school climate of convivencia trough whole school policies. Children and violence: Europe and violence in schoolshow to make a difference. Council of Europe. pp. 41-51.

Swam, R.C., Henry, K.L. and Kelly, K. (2006). Predictors of aggressive behaviors among rural middle school youth. Journal of Primary Prevention, 27, (3), 229-243.

Swearer, S.M., Grills, A.E., Haye, K.M. and Cary, P.T. (2004). Internalizing problems in students involved in bullying and victimization: Implications for intervention. In D.L. Espelage, S.M. Swearer (Eds.), Bullying in American schools (pp. 63-83). New Jersey: Lawrence Erlbaum Associates, Publishers.

Şirvanlı Özen, D. (2006). Akran zorbalığına maruz kalmanın olası yordayıcıları ve cinsiyet ile yaşa bağlı değişim. I.Şiddet ve Okul: Okul ve çevresinde çocuğa yönelik şiddet ve alınabilecek tedbirler sempozyumu bildiri özeti. İstanbul.

Whitaker, D.J., Rosenbluth, B., Valle, L.A. and Sanchez, E. (2004). Expect respect: A school-based intervention to promote awareness and effective responses to bullying and sex harassment. In D.L. Espelage and S.M. Swearer (Eds.), Bullying in American schools: A social-ecological perspective on prevention and intervention (pp. 327-350). New Jersey: Lawrence Erlbaum Associates, Publishers.

Whitted, K.S. and Dupper, D.R. (2005). Best practices for preventing or reducing bullying in schools. Children and Schools, 27, (3), 167-175.

Yang, S.J., Kim, J.M. and Kim, S.W. (2005). Bullying and victimization behaviours in boys and girls at south Korean primary schools. Journal of the American Academy of Child and Adolescent Psychiatry, 45, (1), 69-77.

Yurtal, F. ve Cenkseven, F. (2006). İlköğretim okullarında zorbalı̆̆ın incelenmesi. I. Şiddet ve Okul: Okul ve çevresinde çocuğa yönelik şiddet ve alınabilecek tedbirler sempozyumu bildiri özeti. İstanbul. 